\title{
Pedikül Vidaları İçin PLA Malzeme Kullanımının Mukavemet Açısından Değerlendirilmesi
}

\author{
Talip ÇELiK ${ }^{1}$, Çağatay TAŞDEMiRCi ${ }^{2}$, ibrahim MUTLU ${ }^{1}$, Arif ÖZKAN ${ }^{2}$ \\ ${ }^{1}$ Kocaeli Üniversitesi, Teknoloji Fakültesi Biyomedikal Mühendisliği Bölümü, Kocaeli. \\ Sorumlu yazar e-posta: celiktlp@gmail.com. \\ ORCID ID: http://orcid.org/0000-0003-0033-2454 \\ cagatay.tasdemirci@kocaeli.edu.tr. ORCID ID: http://orcid.org/0000-0002-6471-0867 \\ mutluibrahim@gmail.com. \\ arif.ozkan@kocaeli.edu.tr. \\ ORCID ID: http://orcid.org/0000-0003-3864-3725 \\ ORCID ID: http://orcid.org/0000-0002-1288-6166
}

Geliş Tarihi: 06.03.2021 Kabul Tarihi: 20.08.2021

Öz

Omurga sorunlarında sıklıkla pedikül vida ve rod sistemleri kullanılır. Bu sistemlerin en büyük sorunları vida kırılması ve vida gevşemesidir. Vida ve rod malzemesi olarak halihazırda metalik implantlar kullanılmaktadır ve metalik implantların elastik modüllerinin yüksek olması sebebi ile kemiğe yük aktarımında sıkıntılar oluşabilmektedir. Bu çalışmada, metalik implantlara göre elastiklik modülü daha düşük olan ve son zamanlarda kullanımı artan Polilaktik Asit (PLA) malzemesi ve bu malzemeden oluşturulan Polilaktik Asit/Hidroksiapatit (PLA/HA) kompozit malzemesinin pedikül vidalarında kullanılabilirliği mukavemet yönünden değerlendirilmiştir. Bu amaçla sonlu elemanlar yöntemi kullanılmıştır. T9 omurga modeli MIMICS yazılımı ile oluşturulmuş ve vida-rod modelleri ile ameliyat prosedürüne uygun olarak bilgisayar ortamında birleştirilmiştir. Sonlu elemanlar analizi için pedikül vida malzemeleri Ti6AI4V, PLA ve PLA/HA malzemeleri seçilmiştir. Ayrıca, pedikül vida modeli üzerinde tasarım değiştirerek iki farklı model daha analize katılmıştır. Yapılan 5 farkı analiz sonuçları karşılaştırılmış ve en uygun pedikül malzemesi/tasarımı belirlenmiştir. Sonuç olarak, PLA/HA kompozit malzeme kullanımı yeterli mukavemete ve rijitliğe sahip olmuştur. Ayrıca, vida tasarım değişikliği ile PLA malzemesi pedikül vidalar için kullanılabilir.

\section{Evaluation of the Use of PLA Material for Pedicle Screws in Terms of Strength}

Keywords

Pedicle Screw; Screwrod System; PLA;

PLA/HA; Finite Element Analysis

\begin{abstract}
Pedicle screw and rod systems are frequently used in spinal diseases. The biggest problems of these systems are screw failure and screw loosening. Metal implants are currently used as screw and rod materials, and problems may occur in load transfer to the bone due to the high elastic modulus of metallic implants. In this study, the use of the Polylactic Acid (PLA) material, which has a lower elasticity module compared to metallic implants and has recently increased, and the Polylactic Acid / Hydroxyapatite (PLA / HA) composite material formed from this material, in pedicle screws were evaluated in terms of strength. For this purpose, the finite element method has been used. The T9 spine model was created with MIMICS software and assembled with screw-rod models in a computer environment in accordance with the surgical procedure. Pedicle screw materials Ti6AI4V, PLA, and PLA / HA materials were selected for finite element analysis. In addition, two different models were included in the analysis by changing the design of the pedicle screw model. The results of 5 different analyzes were compared and the most suitable pedicle material/design was determined. As a result, the use of PLA/HA composite material has had sufficient strength and rigidity. Also, with the screw design change, PLA material can be used for pedicle screws.
\end{abstract}




\section{Giriş}

Omurga kırıklarının sabitlenmesinde, spinal füzyonda, skolyoz düzeltme ameliyatlarında sıklıkla pedikül vida ve rod sistemleri kullanılır. Bu sistem omurgalarda meydana gelen hasarları ve kırıkları sabitleyerek sistemin stabilitesini sağlar ve bu sayede gerekli tedavi yapılmış olur. Bu amaçla kullanılan vida ve rod sistemlerinde sıklıkla titanyum alaşımları tercih edilir. Fakat bunun yanında 316L ve 316LVM paslanmaz çelik, 22Cr13Ni-5Mn paslanmaz çelikler de kullanılır. Bu sistemlerde en sık karşılaşılan sorun pedikül vida ve rod kırılmasıdır (Hicks et. al. 2010, Chatzistergos et al. 2010, Eldin ve Ali 2014). Omurga sabitlemelerinde en sık görülen sorunlar \%34 pedikül vida kırılması, \%24 rod kırılması, \%22 rod gevşemesi, \%16 vida gevşemesi, \%4 hem rod hem vida hasarları olarak belirtilmiştir (Eldin ve Ali 2014). Diğer bir çalışmada vida kırılması ve vida gevşemesi en sık görülen sorun olarak bildirilmiştir [(Hicks et. al. 2010, Chatzistergos et al. 2010). Pedikül vida ve rod kırılmaları genellikle aşırı gerilmelerden veya yorulma gerilmelerinden dolayı oluşmaktadır (Puvanesarajah 2014, Newcomb et.al. 2016, Chen et. al. 2003). Ayrıca, kemikte pedikül vida yerleştirilirken deliğin uygun bir şekilde açılmaması da vida hasarlarına yol açmaktadır (Li et. al. 2003). Pedikül vidalarında en sık görülen kırılma hasarı, vidanın boyun bölgesinde, mukavemet açısından en zayıf yerinde görülmektedir (Lai et. al. 2018). Buradan da anlaşılacağı üzere bu tarz sabitleme işlemlerinde en sık görülen problemler vida-rod sistemlerindedir. Bu sebeple, vida-rod sistemlerine alternatif bir sistem geliştirilmeli veya farklı malzemeler ile bu risk azaltılmalıdır.

Ortopedik implant pazarında en çok metalik implantlar satılmaktadır. Wolf kanununda yük taşımayan kemiğin zamanla kütlesini kaybedeceği belirtilir. Bu durum zamanla imlantın gevşemesine yol açar (Shih et. al. 2015). İmplantlarda kullanılanılan metalik malzemelerin elastiklik modülleri kemiğe göre çok yüksektir. İmplantların elastik modülleri 100 ile 300 GPa arasında değişirken, vertebra kortikal kemiğin elastiklik modülü 12 GPa civarındadır (Su et. al. 2018, Basaran et. al. 2019). Bu elastik modüllerindeki yüksek fark zamanla stres kalkanı denilen olaya sebebiyet verir (Çelik and Kisioglu 2020). Bu sebepten dolayı ortopedide kullanılan implantlara alternatif malzeme arayışları devam etmektedir. Son zamanlarda özellikle 3D yazıcıların gelişmesiyle birlikte PLA malzemeye ilgi artmıştır. Ayrıca, PLA malzemenin yüksek biouyumlu olması medikal alanda kullanımını genişletmektedir. Bunun yanında, PLA'nın biyobozunur olması, toksik madde içermemesi, vücut sıvıları ile etkileşime girmemesi sebebiyle büyük avantajlara sahiptir (Leksakul et. al. 2018). Bu avantajlar sebebiyle biyomedikal uygulamalarda son zamanlarda kullanımı artmıştır. Öncelikle düşük mukavemet gerektiren yerlerde plak malzemesi olarak kullanımı başlamıştır. PLA malzemesinin düşük elastik modülü sebebiyle PLA/HA kompozit malzemeler üzerine çalışmalar yapılmış ve içerdiği Hidroksiapatit (HA) sayesinde PLA elastik modülü ve dayanımı arttırılmıştır (Farah et. al. 2016). Bu sayede düşük ve orta dercede mukavemet gerektiren plaklarda kullanılmaktadır.

$\mathrm{Bu}$ çalışmada da omurga sorunlarında sıklıkla kullanılan pedikül vida- rod sistemlerinin en büyük sorunları olan vida ve rod kırılmalar ve gevşemelerine PLA ve PLA/HA malzemeleri kullanımının etkisi değerlendirilmiştir. Araştırma sorusu olarak, "PLA ve PLA/HA malzemelerinin vidarod sistemlerinde kullanılabilir mi?" sorusu belirlenmiştir. Bu amaçla, son zamanlarda sıklıkla tercih edilen ve gerilmelerin rahatlıkla ayrıntılı bir şekilde değerlendirme fırsatı sunan sonlu elemanlar yöntemi seçilmiştir.

\section{Materyal ve Metot}

\section{1 Üç Boyutlu Modelleme}

Omurga modeli oluşturmak için gönüllü bir hastanın Bilgisayarlı Tomografi (BT) görüntülerinden yararlanılmıştır. BT görüntüleri MIMICS 12.0 yazılımı kullanılarak açılmış ve T9 omurgası 3 boyutlu model haline getirilmiştir. Omurga modelinin trabeküler ve kortikal kısımları ayrı ayrı oluşturulmuş ve SolidWorks yazılımına aktarılmıştır. Ayrıca, pedikül vidası ve rod sistemleri de SolidWorks yazılımı kullanılarak modellenmiştir. Pedikül vidasının uzunluğu $45 \mathrm{~mm}$, diş dibi çapı $4 \mathrm{~mm}$, diş üstü çapı $6.5 \mathrm{~mm}$, vida adımı $2.5 \mathrm{~mm}$ olacak şekilde 
tasarlanmıştır. Rod çapı ise $6 \mathrm{~mm}$ 'dir (Basaran et. al. 2019). Modellemeleri yapılan rod, vida ve omurga modelleri SolidWorks yazılımında ameliyat prosedürüne uygun olarak birleştirilmiştir. Birleştirilen model daha sonra Ansys Workbench yazılımına aktarılmıştır. Burada vida ve omurga modellerinde vidanın girdiği bölgelerden hacim çıkarma (substract) işlemi yapılarak omurgada vida girintisi oluşturulmuştur. Ayrıca, pedikül vidasının orta bölgesi Hidroksiapatit (HA) malzemesini enjekte edebilmek ve Ti6Al4V çubuk yerleştirebilmek için boşaltılmıştır. PLA malzemesi kullanıldığında vidanın rijitliğini arttırmak amacıyla 3 $\mathrm{mm}$ çapında delik açılmış ve bu delik içerisine titanyum alaşımlı çubuk ve HA malzemesi yerleştirilmiştir. Oluşturulan modelin farklı yönlerden görünümü ve vida-rod sistemi Şekil 1'de gösterilmiştir.

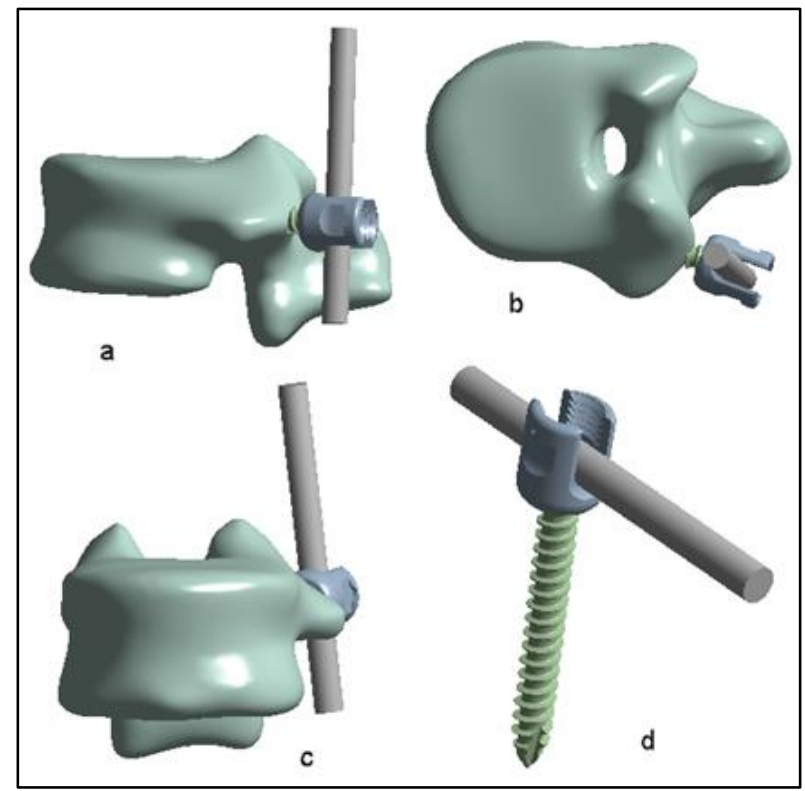

Şekil 1. 3 boyutlu omurga-vida-rod sisteminin lateral (a), superior (b), anterior (c) görüntüleri ve vida-rod sistemi (d)

\subsection{Sonlu Elemanlar Modeli}

Sonlu elemanlar analizi (SEA) için gerekli olan malzeme özellikleri lineer, izotropik ve elastik malzeme olarak belirlenmiş ve Çizelge 1'de gösterilmiştir. Modellemede omurga kemik modeli kortikal ve trabeküler olarak ayrı modellendiği için bu modellere ayrı ayrı malzeme özelliklere tanımlanmıştır (Su et. al. 2018, Basaran et. al. 2019, Farah et. al. 2016, Keller 1994).
Üç boyutlu modellere malzeme özellikleri atandıktan sonra sonlu elemanlar modelleri oluşturmak için meshleme işlemi gerçekleştirilmiştir. Yakınsama çalışması yapılarak en uygun element boyutları belirlenmiştir. Yakınsama çalışmasında modellere farklı element boyutları atanarak analizler gerçekleştirilmiş ve elde edilen gerilme değerleri değerlendirilmiştir. Ayrıca, benzer sonlu elemanlar çalışmaları ile karşılaştırılarak sonuçlar irdelenmiştir (Basaran et. al. 2019). Yakınsama çalışmaları sonucunda omurga modelinin element boyutu $2 \mathrm{~mm}$ ve vida-rod sisteminin element boyutu ise $0.75 \mathrm{~mm}$ olarak belirlenmiştir. Ayrıca, pedikül vida boyun bölgesi gibi gerilmenin yüksek beklendiği bölgelerde daha küçük element boyutunda mesh atılmıştır.

Üç boyutlu sonlu elemanlar modeline Şekil 2'de gösterildiği gibi sınır şartları tanımlanmıştır. Kuvvet, rod üzerinden pedikül vidasını eğilmeye zorlayacak şekilde uygulanmıştır. Kuvvet değeri ise literatürde uygulanmış olan 80 N'un biraz üzerinde $100 \mathrm{~N}$ olarak belirlenmiştir (Tsai et. al. 2019). Omurganın alt ve üst kısımlarından 6 serbestlik derecesinde hareket sıfırlanmış ve bu şekilde sabitleme yapılarak sınır şartı tanımlanmıştır. Modeller arasındaki temaslar, pedikül vida ile kemik bütünleşmesi tamamlandığ varsayılarak yapışkan (bonded) temas tipi seçilmiştir.

Çizelge 1. Sonlu Elemanlar Modeli için kullanılan malzeme özellikleri

\begin{tabular}{lllll}
\hline & $\begin{array}{l}\text { Elastiklik } \\
\text { modülü } \\
\text { (MPa) }\end{array}$ & $\begin{array}{l}\text { Poisso } \\
\mathbf{n} \\
\text { oranı }\end{array}$ & $\begin{array}{l}\text { Akama } \\
\text { Mukaveme } \\
\text { ti (MPa) }\end{array}$ & $\begin{array}{l}\text { Referan } \\
\text { s }\end{array}$ \\
\hline $\begin{array}{l}\text { Titanyum } \\
\text { alaşımı }\end{array}$ & 113000 & 0.33 & 862 & {$[11,12]$} \\
\hline PLA & 3500 & 0.36 & 70 & {$[15]$} \\
\hline $\begin{array}{l}\text { PLA/HA } \\
\text { kompozit }\end{array}$ & 10000 & 0.34 & 130 & {$[15]$} \\
\hline HA & & 0.30 & $>100$ & {$[11,12$,} \\
\hline $\begin{array}{l}\text { Omurga/Kort } \\
\text { ikal }\end{array}$ & 12000 & 0.20 & - & {$[11,12]$} \\
\hline $\begin{array}{l}\text { Omurga/Trab } \\
\text { eküler }\end{array}$ & 100 & & & \\
\hline
\end{tabular}

\section{Bulgular}

SEA sonuçlarını değerlendirmek için iki önemli kriter belirlenmiştir. Bu kriterler; malzeme mukavemetini değerlendirmek için kullanılan eşdeğer gerilme ve modellerin rijitliğini belirlemede önemli bir değer olan deformasyon miktarıdır.

Modeller üzerinde oluşan von Mises gerilme dağılımları Şekil 3'te gösterilmiştir. Pedikül vida 
malzemesi PLA ise model ismi PLA, PLA/HA kompozit malzemesi ise PLA/HA, Ti6Al4V ise Ti6Al4V olarak adlandırılmıştır. Ayrıca, PLA pedikül vida içerisine HA yerleştirilmiş modele PLA-HA ve titanyum alaşımlı çubuk yerleştirilmiş modele ise PLA-Titanyum olarak isimlendirilmiştir. Beş farklı sonlu elemanlar analizinde en yüksek von Mises bileşik gerilme değeri 97.79 MPA ile PLA/HA modelinde vida baş parçası üzerinde elde edilmiştir. En düşük maksimum gerilme değeri ise $76.83 \mathrm{MPa}$ ile PLA-Titanyum modelinde ve pedikül vida üzerinde hesaplanmıştır. Sonlu elemanlar analizi ile elde edilen maksimum von Mises gerilme değerleri karşılaştırmalı olarak Çizelge 2'de gösterilmiştir. Omurga kemiği üzerinde oluşan maksimum gerilme değeri 76.30 MPa ile PLA-HA modelinde oluşmuştur. Pedikül vida malzemesi olarak sadece PLA malzemesi seçildiğinde kemiğe aktarılan gerilme değeri 50.03 MPa'ya düşmektedir. PLA/HA kompozit malzemesi seçildiğinde ise omurgada oluşan gerilme değeri 28.85 $\mathrm{MPa}$ değerine inmektedir. PLA-Titanyum ve Titanyum alaşımı kullanıldığında ise kemik üzerinde sırasıyla 7.87 ve $7.92 \mathrm{MPa}$ gerilme hesaplanmıştır. Bu sonuca göre kemik için en kritik model PLA-HA modelidir. Maksimum gerilme sonuçları pedikül vida için değerlendirilirse, maksimum von Mises gerilme değeri 76.83 MPa ile PLA-Titanyum modelinde çıkmıştır. En düşük gerilme ise 34.70 MPa ile PLA/HA modelinde elde edilmiştir.

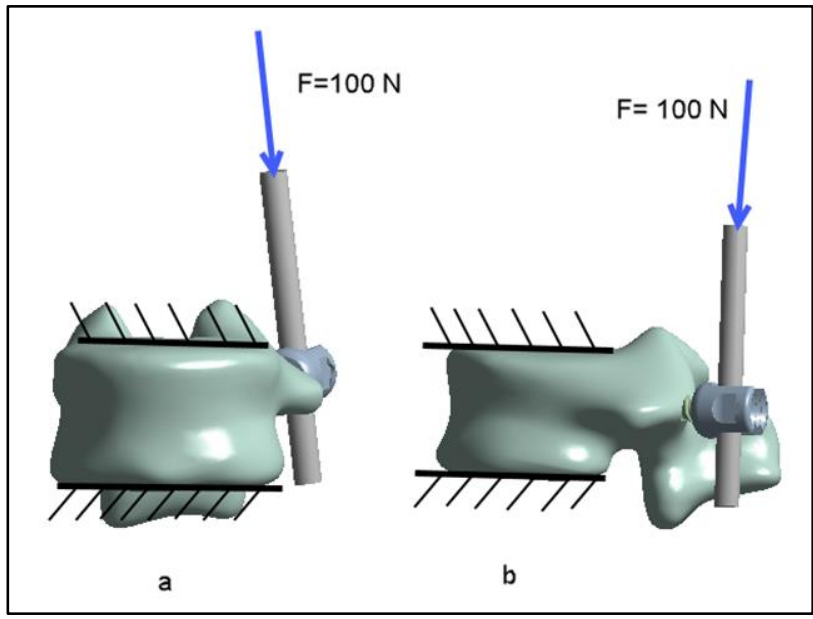

Şekil 2. 3 boyutlu omurga-vida-rod sisteminin lateral (a), superior (b), anterior (c) görüntüleri ve vida-rod sistemi (d)

$\mathrm{Bu}$ sonuçları mukavemet açısından daha iyi irdeleyebilmek için her bir modelin güvenlik katsayıları hesaplanmıştır. Çizelge 1'deki akma mukavemet değerleri referans alınarak hesaplanan güvenlik katsayıları, omurga-rod sisteminin kullanılabilirliğini göstermektedir (Çizelge 2). Bu değerlere göre, PLA-Titanyum modelinde elde edilen en düşük güvenlik katsayısı 0.91 ile pedikül vidada hesaplanmıştır. Pedikül vidası tanımlanan sınır şartlarına göre bu model de hasara uğrayacaktır. Bu sebeple PLA-Titanyum modeli, yani PLA pedikül vidası içerisine Ti6Al4V çubuğunu yerleştirmek mukavemet açısından olumsuz sonuç vermiştir. Diğer yandan PLA-HA modelinde ise güvenlik katsayısı 1.31 ile omurga modelinde hesaplanmıştır. Pedikül vida için PLA/HA kompozit malzemesi seçilmesi sonucunda ise en düşük güvenlik katsayısı $3.46^{\prime}$ dır. Bu değer sistemin yaklaşık 3.5 kat güvenli olduğunu göstermektedir. Sadece PLA malzemesi seçilmesi ile de en düşük güvenlik katsayısı 1.98 çıkmıştır. Yani bu sistemde yaklaşık 2 kat güvenlidir. Ti6Al4V malzemesi seçiminde ise en iyi sonuçlar alınmaktadır. Bu sistem için de güvenlik katsayısı 9.47'dir. Gerilme sonuçlarına göre en iyi sonuç veren modeller sırası ile Ti6Al4V, PLA/HA, PLA ve PLA-HA'dır. PLATitanyum modelinde elde edilen sonuçlara göre mukavemeti yetersiz kalmıştır.

Omurga kırıklarında esas olan rijitliktir. Bu sebeple sistemde oluşan total deformasyon miktarları da incelenmiştir. Buna göre en rijit model beklendiği üzere Ti6Al4V modelidir. Bu modele en yakın rijitlik sunan model ise PLA-Titanyum modelidir, fakat bu model mukavemet açısından yetersiz kaldığı için kullanılamaz. PLA/HA modelinde $0.067 \mathrm{~mm}$ deformasyon hesaplanmıştır ve rijitlik açısından Ti6Al4V modeline en yakın sonuç vermiştir. PLA-HA modelinde ise toplam deformasyon $0.125 \mathrm{~mm}$ 'dir. Fakat bu modelde de mukavemet yönünden zayıf çıkması sebebiyle rijitlik önemini yitirmiştir. Son olarak sadece pedikül vida için PLA malzemesi seçilmesi her ne kadar mukavemet açısından yeterli görünse de sistem rijitliğini sağlayamamıştır. Bu modelde toplam deformasyon $0.132 \mathrm{~mm}$ hesaplanmıştır. Bu da referans model olan Ti6Al4V modeline göre yaklaşık 6 kat daha az rijit olması anlamına gelmektedir. 


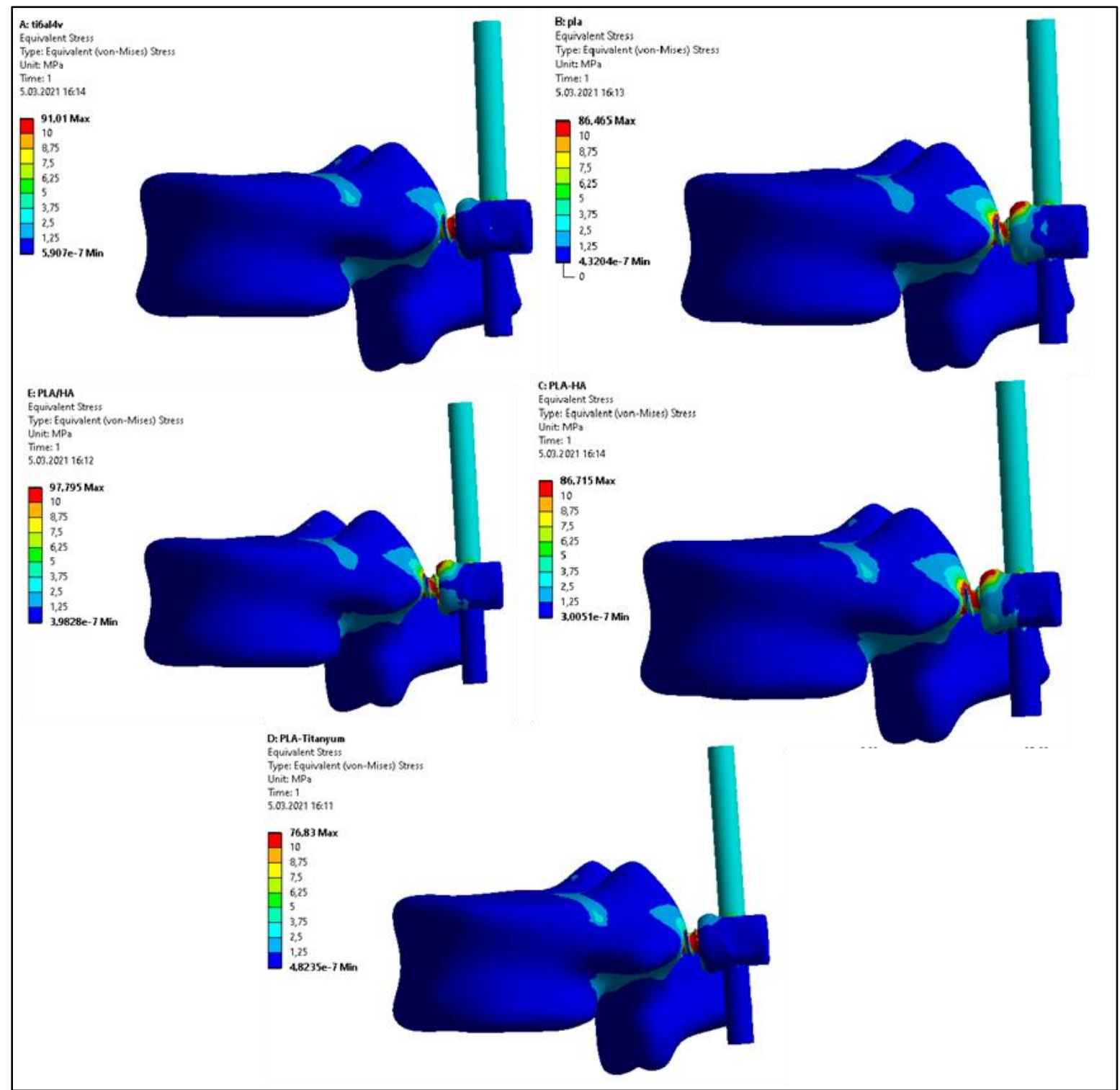

Şekil 3. Maksimum gerilme dağılımları ve değerleri

Çizelge 2. Sonlu Elemanlar Modeli için kullanılan malzeme özellikleri

\begin{tabular}{|c|c|c|c|c|}
\hline $\begin{array}{l}\text { Pedikül vida } \\
\text { malzemesi }\end{array}$ & Model & $\begin{array}{l}\text { Maksimum von } \\
\text { Mises gerilmesi } \\
\quad(\mathrm{MPa})\end{array}$ & $\begin{array}{l}\text { Güvenlik } \\
\text { Katsayısı }\end{array}$ & $\begin{array}{l}\text { Total Deformasyon } \\
(\mathrm{mm})\end{array}$ \\
\hline \multirow{5}{*}{ Ti6Al4V } & Omurga & 7.92 & 12.62 & \multirow{5}{*}{0.0221} \\
\hline & Pedikül Vida & 60.56 & 14.23 & \\
\hline & & & & \\
\hline & Vida baş parçası & 91.01 & 9.47 & \\
\hline & Rod & 20.28 & 42.50 & \\
\hline \multirow{5}{*}{ PLA } & Omurga & 50.03 & 1.99 & \multirow{5}{*}{0.132} \\
\hline & Pedikül Vida & 35.28 & 1.98 & \\
\hline & & & & \\
\hline & Vida baş parçası & 86.46 & 9.97 & \\
\hline & Rod & 12.12 & 71.12 & \\
\hline
\end{tabular}




\begin{tabular}{|c|c|c|c|c|}
\hline \multirow{4}{*}{$\begin{array}{l}\text { PLA/HA kompozit } \\
\text { malzemesi }\end{array}$} & Omurga & 28.85 & 3.46 & \multirow{4}{*}{0.067} \\
\hline & Pedikül Vida & 34.70 & 3.74 & \\
\hline & Vida baş parçası & 97.80 & 8.81 & \\
\hline & Rod & 14.28 & 60.36 & \\
\hline \multirow{4}{*}{$\begin{array}{l}\text { PLA vida içerisine HA } \\
\text { enjekte edildiğinde }\end{array}$} & Omurga & 76.30 & 1.31 & \multirow{4}{*}{0.125} \\
\hline & Pedikül Vida & 41.10 & 1.70 & \\
\hline & Vida baş parçası & 86.72 & 9.94 & \\
\hline & Rod & 29.01 & 29.71 & \\
\hline \multirow{5}{*}{$\begin{array}{l}\text { PLA vida içerisine } \\
\text { Ti6Al4V çubuk } \\
\text { yerleştirildiğinde }\end{array}$} & Omurga & 7.87 & 12.70 & \multirow{5}{*}{0.0227} \\
\hline & Pedikül Vida & 76.83 & 0.91 & \\
\hline & & & & \\
\hline & Vida baş parçası & 57.61 & 14.96 & \\
\hline & Rod & 19.82 & 43.49 & \\
\hline
\end{tabular}

\section{Tartışma}

Bu çalışma kapsamında son zamanlarda, özellikle 3B yazıcıların gelişmesi ile daha çok kullanılan PLA malzemesinin, omurga pedikül vidası olarak kullanımının uygunluğu araştırımıştır. Bu amaçla, sonlu elemanlar yöntemi kullanılarak modelleme ve analizler gerçekleştirilmiş ve elde edilen deformasyon ve gerilme değerleri incelenmiştir.

PLA malzemesi biyouyumluluğu yüksek bir malzemedir. Bu özelliğinin yanında dokular ile hızı bütünleşebilmektedir. Metalik implantlarda her ne kadar biyouyumlu malzemeler kullanılsa da, bu malzemelerin doku ile bütünleşmesi zaman almaktadır. Bazı metal malzemelerde ise doku ile bütünleşme olmamaktadır. Bundan dolayı ortopedik implantlarda stres kalkanı ve aseptik gevşeme gibi sorunlar sıklıkla karşılaşılmaktadır. Bu sorunları önlemek için birçok çalışma yapılmıştır (Çelik and Kişioğlu 2019). Metalik implantların elastik modüllerinin kemik malzemesi elastik modülüne göre çok yüksek olması gerilme aktarımında sorunlara yol açmaktadır. Wolf kanununa göre yük aktarımı olmayan ya da diğer deyişle gerilme oluşmayan kemik zamanla zayıflar. işte bu sebeple kemiğe yerleştirilen her implant, kuvvet aktarımını kemik sisteminin doğal yük aktarımına en uygun olacak şekilde tasarlanmalıdır (Toktaş vd. 2017). Tasarımın yanında uygun malzeme seçimi de çok önemlidir. Metalik implantlar içinde en çok biyouyumlu olan titanyum alaşımlarıdır ve ortopedi camiası için bu malzeme altın standarttır. Fakat, bu malzemede de sorunlar bulunmaktadır. Literatürde omurga pedikül vidalarında en sık karşılaşılan sorunun vida kırılması olduğu bildirilmiştir (Hicks et. al. 2010, Chatzistergos et al. 2010, Eldin ve Ali 2014). Bu hasarın sebebi ise vida üzerinde oluşan aşırı gerilmeler veya tekrarlı yüklemeler sonucunda malzeme yorulmalarıdır. Yine omurga sabitlemelerinde karşılaşılan en önemli sorunlardan biri vida gevşemesidir (Eldin ve Ali 2014). Bu sorunun sebebini Wolf kanunu ile açıklamak mümkündür. Metalik implantlarda kemiğin bazı bölgelerine yeteri kadar gerilme aktarılamayabilir ve bu da kemiğin o bölgesinden zayıflaması anlamına gelir. Özellikle gevşeme sorununu, vida tasarımını değiştirmek veya pedikül vidasını daha esnek bir malzeme ile üretmek ile giderilebilir. Kemiğe yük aktarmak için elastik malzemesi düşük malzeme gerekirken, sistemin rijitliğini de korumak da gerekmektedir. Vida malzemesinin elastik modülünü düşürdükçe sistemin stabilitesi de azalmaktadır. Bu sebepten dolayı, bu çalışmada 4 farklı model sunulmuştur. Referans olarak halihazırda kullanılan Ti6Al4V malzemesi pedikül vidası için seçilmiştir. Diğer sunulan modellerde ise PLA ve PLA/HA malzeme kullanımlarında mukavemet yönünden kayıp olsa da hasar oluşmayacağı tespit edilmiştir. Fakat, PLA malzemesinde sistemin rijitliği yaklaşık 6 kat azalmıştır. Bu rijitlik azalmasını değerlendirmek için, tüm omurga modellenmeli ve kırık olan omurga 
üzerine aktarılan yük tespit edilmelidir. Böyle bir çalışma ile bu rijitlik kaybının uygunluğunun değerlendirilmesi mümkün olacaktır.

Omurga kırıklarının sabitlemesinde kısa ve uzun segment sabitlemeleri kullanılmaktadır. Bu segmentler arasındaki mekanik performansı değerlendiren bir çalışmada maksimum vida gerilme değeri $133 \mathrm{MPa}$ olarak hesaplanmıştır (Basaran et. al. 2019). Sınır şartları olarak öne ve yana eğilmeyi simüle eden çalışmada kuvvet ile birlikte moment de uygulanmıştır. Farklı bir çalışmada ise sisteme $300 \mathrm{~N}$ eksenel kuvvet seçilmiştir ve pedikül vidası üzerinde maksimum $112 \mathrm{MPa}$ gerilme hesaplandığı bildirilmiştir (Wang et. al. 2019). Literatürde verilen bu çalışmalar birden fazla omurga modellenerek gerçekleştirilmiştir. Yani uygulanan yük ve moment değerleri bütün sisteme etkilemektedir. Deneysel olarak yapılan bir diğer çalışmada, pedikül vida tasarımlarının dayanımını belirlemek için sentetik omurga modeline sabitlenen pedikül vidaya rod üzerinden $80 \mathrm{~N}$ kuvvet uygulanmıştır (Tsai et. al. 2009). Bu çalışmada ise tek omurga modellenmiş ve $100 \mathrm{~N}$ eksenel kuvvet rod üzerine uygulanmıştır. Bu sınır şartlarına göre pedikül vida üzerinde maksimum $76.83 \mathrm{MPa}$ gerilme hesaplanmıştır. Pedikül vidası üzerinde oluşan maksimum gerilmeler literatür ile uyumlu olarak vida boyun bölgesinde elde edilmiştir.

Rod üzerinde meydana gelen maksimum gerilme değerleri incelendiğinde, rod ile vida baş parçası arasında kalan temas bölgesinde maksimum gerilmenin meydana geldiği görülmüştür. Literatürde de aynı bölgelerde gerilme hesaplanmıştır. Yine kısa ve uzun segment sabitleme yönteminin değerlendirildiği çalışmada rodlar üzerinde eksenel yüklemede maksimum $36.82 \mathrm{MPa}$, lateral eğilmede ise $48.12 \mathrm{MPa}$ gerilme hesaplanmıştır (Wang et. al. 2019). Bu çalışmada ise, eksenel yükleme uygulanmış ve $29.01 \mathrm{MPa}$ gerilme elde edilmiştir. Bu aradaki fark, bu çalışmada sadece tek omurga üzerinde tek kısa rod kullanılarak değerlendirme yapıldığı için ortaya çıkmıştır. Bu çalışma için uygulanan sınır şartları ve kuvvet değerleri yine literatürde yapılmış olan deneysel çalışmadan alınmıştır (Weiser et. al. 2017).

PLA/HA malzemesi, PLA malzemesi içerisine HA partiküllerinin belirli oranlarda karıştırılark elde edilen kompozit bir malzemedir. PLA/HA malzeme içeriğinde HA oranı arttıkça elastik modülü ve malzeme dayanımı artmaktadır (Farah et. al. 2016). Bu tür kompozit ve biyouyumlu malzemeler ileride metalik implantlar yerine geçme potansiyeline sahiptir. Bu tür malzemelerin plak ve vida amaçlı kullanımları artmaktadır. Kemik hasarlarında özellikle yüksek dayanım gerektirmeyen üst ekstremite kırık sabitlemelerinde PLA malzemesinin kullanımı literatürde değerlendirilmiştir (Leksakul et. al. 2018). Çalışmada, el bileği kırıklarında kullanılacak plağın PLA malzemesi kullanıldığında mekanik performans etkileri değerlendirilmiştir. Bu değerlendirmede özellikle düşme ve çarpma durumlarında bu plağın kırılacağı tespit edilmiştir (Leksakul et. al. 2018). Fakat, bu tarz kırıkların çarpma ve düşme gibi durumlarda metalik implant kullanımında da etkisi değerlendirilmelidir. Metalik implant kullanımında da düşme, çarpma gibi durumlarda plak kırılması ile karşılaşılabilir. Literatürde, omurga vida-rod sistemlerinde PLA ve PLA/HA malzemesinin kullanılmasının mekanik etkisi değerlendirilmemiştir. Bu çalışma da bu konu üzerine çalışılmıştır.

PLA ve PLA/HA malzemesi ile gerçekleştirilen analiz sonucunda pedikül vidanın güvenlik katsayısının düştüğü sonuçlar bölümünde ifade edilmişti. Bu çalışmada, tasarımsal olarak aynı olan pedikül vidanın malzeme farklılıklarında değerlendirilmesi yapılmıştır. Özellikle PLA pedikül vidasında rijitliğin düşmesini farklı yöntemlerle giderilebilir. Mesela, tasarımsal olarak pedikül vidanın değiştirilmesi sistem rijitliğini arttırabilir. Ayrıca, pedikül vidası ile baş parçası ameliyat esnasında cerrahın kemiğe vidanın daha rahat yerleştirmesi için ayrı ayrı üretilmektedir. Bu sayede vida baş kısmı hareketli olmaktadır. Fakat bu hareketi sağlarken vida mukavemetinden de taviz verilmektedir. Vida boyun bölgesi daha düşük çapa sahip olacak şekilde tasarlanmaktadır. Bu sebepten dolayı yeni bir pedikül vida tasarımı ile PLA malzemesi kullanımında ortaya çıkan rijitlik düşmesini en aza indirmek mümkün olabilir.

Bu çalışmanın bazı eksik yönleri vardır. Bunlardan birisi, sadece T9 omurga modeli üzerinde değerlendirme yapılmasıdır. Bütün omurga üzerinde modelleme yapılarak analizlerin gerçekleştirilmesi daha uygun olabilirdi. Fakat sonlu elemanlar yönteminde basitleştirme esastır ve bu basitleştirmeyi tüm modelin bir parçası olarak kurgulanmıştır. Ayrıca literatürdeki benzer tüm modeller üzerinde yapılan analiz sonuçları ile karşılaştırıldığında elde edilen sonuçların uyumlu olduğu görülmektedir. 


\section{Sonuç}

Bu çalışma ile aşağıdaki sonuçlar çıkarılmıştır;

PLA pedikül vidası titanyum vidalara alternatif olabilir, fakat tasarım yönünden iyileştirilerek mukavemetinin ve rijitliğinin arttırılması gereklidir.

PLA/HA malzemesi, PLA malzemesine göre pedikül vida kullanımına daha uygundur. Aynı şekilde bu malzeme için mukavemetinin arttrılması olası mekanik hasarlar riskini azaltacak ve sistemin rijitliğini artıracaktır.

PLA veya PLA/HA malzemesi kullanımında kemiğe aktarılan gerilme değerleri yükselmektedir. Bu da kemik zayıflamasının önüne geçerek gevşeme sorununu giderebilir.

\section{Kaynaklar}

Basaran, R., Efendioğlu, M., Kakşi, M., Çelik, T., Mutlu, I., and Uçar, M., 2019. Finite Element Analysis of ShortVersus Long-Segment Posterior Fixation for Thoracolumbar Burst Fracture. World Neurosurgery, 128, 1109-1117.

Chen, S.I., Lin R.M., and Chang C.H., 2003. Biomechanical investigation of pedicle screw-vertebrae complex: a finite element approach using bonded and contact interface conditions. Medical Engineering \& Physics, 25(4), 275-282.

Chatzistergos, P.E., Magnissalis E.A. and S.K. Kourkoulis, 2010. A parametric study of cylindrical pedicle screw design implications on the pullout performance using an experimentally validated finite-element model. Medical Engineering \& Physics, 32(2), 145-154.

Çelik, T. and Y. KişioĞLU,2021. New Hip Prosthesis Design and Evaluation with Using Finite Element Analysis. Journal of Polytechnic, 31, 10-20.

Çelik, T. and Y. Kişioğlu, Evaluation of new hip prosthesis design with finite element analysis, 2019. Australasian Physical \& Engineering Sciences in Medicine, 42(4), 1033-1038.

Çelik, T., Mutlu, I, Ozkan, A., and Kisioglu Y., 2017. The effect of cement on hip stem fixation: a biomechanical study. Australasian Physical \& Engineering Sciences in Medicine, 40(2), 349-357.
Farah, S., D.G. Anderson, and R. Langer, 2016. Physical and mechanical properties of PLA, and their functions in widespread applications - A comprehensive review. Advanced Drug Delivery Reviews, 107, $367-$ 392.

Hicks, J.M., Singla, A., Shen, F.H. and Arlet, V., 2010. Complications of Pedicle Screw Fixation in Scoliosis Surgery. Spine, 35(11), 465-470.

Keller, T.S., Predicting the compressive mechanical behavior of bone, 1994. Journal of Biomechanics, 27(9), 1159-1168.

Lai, D.M., Shih, Y.T., Chen Y.H., Chien H. and Wang, J.L., 2018. Effect of pedicle screw diameter on screw fixation efficacy in human osteoporotic thoracic vertebrae. Journal of Biomechanics, 70, 196-203.

Leksakul, K. and M. Phuendee, 2018. Development of hydroxyapatite-polylactic acid composite bone fixation plate. Science and Engineering of Composite Materials, 25(5), 903-914.

Li, S., Wahab, A.A., Demirci E., Silbertschmdit, V., 2014. Penetration of cutting tool into cortical bone: Experimental and numerical investigation of anisotropic mechanical behaviour. Journal of Biomechanics, 47(5), 1117-1126.

Mohi Eldin, M.M. and Ali A.M.A., 2014. Lumbar Transpedicular Implant Failure: A Clinical and Surgical Challenge and Its Radiological Assessment. Asian Spine Journal, 8(3), 281-297.

Newcomb, A.G.U.S., Seungwon Baek, M.S., Brian P. K. and. Crawford N. R, 2016. Effect of screw position on load transfer in lumbar pedicle screws: a nonidealized finite element analysis. Computer Methods in Biomechanics and Biomedical Engineering, 20(2), 182-192.

Puvanesarajah, V., 2014. Techniques and accuracy of thoracolumbar pedicle screw placement. World Journal of Orthopedics, 5(2), 112-123.

Santiuste, C., Millan R.M., Giner E., Miguelez H., 2014. The influence of anisotropy in numerical modeling of orthogonal cutting of cortical bone. Composite Structures, 116, 423-431. 
Shih, K.S., Hsu, C.C., Hou, S.M., Yu, S.C., and Liaw, C.K., 2015. Comparison of the bending performance of solid and cannulated spinal pedicle screws using finite element analyses and biomechanical tests. Medical Engineering \& Physics, 37(9), 879-884.

Su, Y., Wang, X., Ren D., Liu, Y., Liu S. And Wang P., 2018. A finite element study on posterior short segment fixation combined with unilateral fixation using pedicle screws for stable thoracolumbar fracture. Medicine, 97(34), 1260.

Toktaş İ., Özkan M. T. and Çetindağ H.A., 2017. Burkulma Mukavemetine Göre Eşit Miktarda Filament Kullanımı Ile 3 Boyutlu Baskısı Yapılacak Ankastre Kirişlerin Kesit Geometri Biçimlerinin Performansı, Gazi University Journal of Science: Part C, 5(4): 169-177.

Tsai, W.-C., Chen, P.Q., Lu, T.W., Wu, S.S., Shih, S.H. and Li, S.C., 2009. Comparison and prediction of pullout strength of conical and cylindrical pedicle screws within synthetic bone. BMC Musculoskeletal Disorders, 10(1), 1-10.

Wang T., Zhao Y., Cai Z., Wang W., Xia Y., Zheng G., Liang Y. and Wang Y., 2019. Effect of osteoporosis on internal fixation after spinal osteotomy: A finite element analysis, Clinical Biomechanics, 69, 178-183.

Weiser L., Huber G., Sellenschloh K., Viezens L., Püschel K., Morlock M.M. and Lehmann W., 2017. Insufficient stability of pedicle screws in osteoporotic vertebrae: biomechanical correlation of bone mineral density and pedicle screw fixation strength, Eur Spine J, 26(11), 2891-2897. 